\title{
Collaboration: A Partnership Solution in Rural Education
}

\author{
Hobart L. Harmon \\ Virginia Advanced Study Strategies, Inc. \\ and \\ Institute for the Advancement of Research, Innovation and Practice in Rural Education at the University of Central \\ Florida
}

As an introduction to this special issue of The Rural Educator on the topic of collaboration, I provide examples of how collaboration offers promise as a partnership solution to current and future education challenges of rural schools and their communities. Highlights of two literature reviews establish a historical context for collaboration. Specific examples of collaboration in rural education practice from the literature set the stage for a summary of the four articles included in the special issue. Last, five questions are posed that if answered could demonstrate the potential value of collaboration to advance research, innovation and practice in rural education.

This special issue of The Rural Educator journal provides examples of how collaboration is a promising solution to challenges in rural education. One could argue that collaboration is an old strategy whose time has come, again. Times change. What makes collaboration the solution for the times? In this introduction to the special issue, I highlight two literature reviews on collaboration, provide examples of collaboration specific to rural education practice, and then summarize key points by authors of the four articles in this special issue on collaboration. Last, I pose five questions that if answered could demonstrate the potential value of collaboration to advance research, innovation and practice in rural education.

\section{Literature Highlights}

Using the term "collaboration" to search the ERIC data base, which was established in the early 1960s, reveals the data base includes more than 30,000 documents on the topic. Almost 5,200 are specific to elementary and secondary education. More than 5,000 documents have been published in the last 5 years (since 2003). And almost 3,000 documents are associated with the ERIC descriptor of "partnerships in education."

Kinsella-Meier \& Gala (2016) report "what is often labeled 'collaboration' may instead be simply a partnership or one of several levels of a working relationship in which different parties invest different degrees of involvement and time" (p. 4). After a review of the literature, Kinsella-Meier \& Gala concluded there are four levels of partnerships: (1) communication, (2) coordination, (3) cooperation, and (4) collaboration. Level of involvement by partners defines the type of partnership in a project. The amount of autonomy required by each partner, amount of time working together, and degree of interdependency among the partners define the partnership type. Collaboration occurs when individuals within two or more organizations evolve deep and complex interactions in communications to achieve common goals that are interdependent, long term, and complex. Such collaboration taps expertise in the organizations that often results in a new service or product (Kinsella-Meier \& Gala, 2016). Thus, collaboration is the highest level of partnership, compared to communication, coordination and cooperation levels. Collaboration requires greater levels of partner involvement and investment of time. In a literature review more than two decades before Kinsella-Meier and Gala (2016), Mattessich and Monsey (1992) found that collaboration was becoming a "hot topic" among human service, government and community organizations. Autonomy and "going it alone" were no longer perceived as the solution to mission challenges of the organization in an increasing environment of declining resources. A key benefit of collaboration was organizational gains in making services more accessible and effective in a time of declining resources. In identifying 19 factors that influence the success of collaboration, the intent of Mattessich and Monsey (1992) was to offer "accessible research material to anyone who wants to start a collaborative effort or better manage one in progress" (p. 11).

\section{Rural Education Examples}

Collaboration created by regional education service agencies (ESAs) has long been a key strategy for increasing the limited school improvement capacity of rural school districts (Stephens, 1998). The vast majority of states that formed ESA-type organizations, beginning in the 1930s, desired collaborative efforts among school districts to increase economies of scale and bring capacity of 
services to schools and students that a rural school system seldom could achieve alone (Stephens and Keane, 2005). Cost savings of state networks of ESAs particularly enabled rural school districts to access critical programs and services (Stephens \& Harmon, 1996). Today, more than 500 ESA-type organizations operate in 45 states (AESA, 2017).

Formal organization of an ESA is one way collaboration may result in meeting needs of rural districts and their schools. Numerous additional examples exist in the literature that place collaboration as the central strategy for addressing a key rural education challenge. For example, Chance and Segura (2009) reveal how a school's collaborative approach was associated with improved and sustained student achievement in a rural high school. The researchers found successful collaboration included three essential elements: (1) scheduled time for teacher collaboration; (2) structured and focused collaboration time devoted to improving instruction and student achievement, and (3) leadership behaviors that focused on studentcentered planning and accountability. The researchers also found that relationship and contextual factors associated with rural schools and small communities were advantageous in developing a collaborative process for school improvement.

Collaboration among schools can contribute to important school improvement. For example, Muijs (2015) found that school-to-school collaboration as a school improvement method has grown in importance in recent years. Some evidence shows such collaboration can have a positive impact on both capacity to change and student attainment.

School and university collaboration can result in supports that enable teachers within a school to grow as teacher leaders (Eargle, 2013). Collaboration can also enable teachers of gifted students to acquire necessary professional development (Green, 2013). Online collaboration can allow novice teachers to gain ideas and curriculum materials, to overcome lack of preparation and support, to enhance the classroom environment, and to share ideas and resources (Moser, 2012).

Walker (2012) reports how a rural school district collaborated with organizations in the local community to meet the needs of English language learners after the district and community experienced rapid ethnic diversification. Other examples in the literature include how collaboration can help address the social-emotional learning (SEL) needs of students, an increasingly important challenge in rural schools and communities. For example, interdisciplinary collaboration among several rural school districts in a large county may be essential for meeting SEL needs of students (Meyers, Tobin, Huber, Conway \& Shelvin, 2015)

Butler (2008) found rural school and community collaboration is essential if the community is to implement a community development initiative that addresses challenges and opportunities in an increasingly globalized society. Harmon and Schafft (2009) argue that it is this essential collaborative leadership that will enable rural schools and their communities to meet mutually beneficial goals in the global economy era.

Lastly, seeking solutions to critical issues of practice increasingly requires longer term mutual collaborations between education researchers and practitioners. Rural education examples include the research alliances or partnerships of the federallysupported network of regional education laboratories. Also, collaboration as a partnership strategy is becoming more common in research and development (R\&D) projects that seek to innovate solutions to important rural education challenges. Examples include two projects directed by the author and funded by the U.S. Department of Education's investing in innovation (i3) program and additional private sector support: the Rural Math Excel Partnership, and the Rural Math Innovation Network. In additional to the U.S., collaboration between practitioners and researchers in research and development $(\mathrm{R} \& \mathrm{D})$ projects is also increasing (for example, Dutch secondary schools; see Schenke, van Driel, Geijsel, Sligte, \& Volman, 2016).

\section{Special Issue Examples}

The previous examples illustrate how collaboration is embraced in numerous ways to solve or address important challenges in rural education. In this section, highlights of the four articles in this special issue should encourage the reader to closely examine each article for the contributions collaboration can make in solving an important rural education issue or challenge.

In the first article, Preston and Barnes report results of their literature review to identify the professional competencies and personal qualities commonly associated with successful leadership in rural schools. The researchers seek to serve researchers, policymakers, educators, and community members interested in recognizing the effective attributes of rural principals. They examine work published from 2005 to 2015 . Most works were small case studies, with a focus on principals in the United States, Canada, or Australia.

Two themes emerge from the literature review. Successful rural principals promote people-focused relationships with staff, students, parents, and 
community members. Second, rural principals have the opportunity to be agents of change through balancing local and district policies and through enacting instructional leadership. Both of these themes reveal the importance of collaboration with members of the school community. Authors of the article maintain collaborative leadership recognizes the best in people and uses the constructive power of the school community to promote, produce, and publicize student success and well-being. The authors call for further research to more fully understand the collaborative place-conscious role of school leaders in rural schools.

In the second article, Hartman reports the results of a case study that examines the successful collaborative partnership between a first year academic coach and a fifth-grade teacher in a rural school district in northern Appalachia. The researcher sought to answer three questions: (1) What characteristics contribute to the development and sustainment of a rural school collaborative partnership? (2) How do rural school dynamics impact collaborative partnerships? And (3) what motivates participants to continue collaborative partnerships? The district was $98.8 \%$ Caucasian in racial makeup. Nearly $65 \%$ of students received free/reduced lunches and about $25 \%$ of the study body received special education services.

During the 2010-2011 school year, the researcher made 34 site visits to conduct informal and formal interviews, make observations, collect artifacts, and compile detailed field notes. The researcher found that developing and maintaining a collaborative partnership in the rural school was influenced by seven characteristics, five of which were impacted by considerations specific to rurality. Characteristics directly influenced by rurality include life experiences, willingness to change, trust and confidentiality, respect, and persistence. In addition, the researcher notes a school administrator should be aware of the impact that professional isolation plays in rural school collaborative partnerships, and may find that academic coaches are helpful in mitigating its effects.

In the third article, Willis and Templeton provide $\backslash$ results of a qualitative study to explore factors that principals in rural East Texas deem most crucial to establishing and maintaining professional learning communities (PLCs). Five research questions guide the study, including questions about how the factors can be applied to improve the effectiveness and increase the sustainability of PLCs in rural schools.

The researchers interviewed seven principals, each with at least three years of experience as principal at the respective campus. The seven principals were selected from different school campuses in the same Texas education service center region. All principals were Caucasian, five were male and two were female. Among the researchers' findings was principals' emphasis on three factors that influence the effectiveness of PLCs: (1) continually recognizing goals, (2) providing time for teachers to collaborate, and (3) communicating with and among teachers. The researchers conclude the most common factor among principals' perceptions in successful establishment and sustainability of PLCs is time for teachers to collaborate or meet as a leadership team.

In the fourth article, Nichols, Goforth, Sacra, and Ahlers describe the importance of collaboration between rural educators and support personnel (i.e., school counselors and school psychologists) in meeting mental health issues of students in rural and Native American communities. Several factors make support of children in rural or tribal communities particularly challenging, such as:

- dynamic professional roles in schools (e.g., professional “turf”),

- community stigma associated with mental health (e.g., unsupportive cultural values and norms),

- ethical and legal challenges associated with mental health (i.e., issues of multiple relationships and confidentiality), and

- need to provide culturally competent and relevant services to rural and tribal communities.

Moreover, collaboration is difficult in schools where distance and schedules limit or prevent interaction. This is often the case when school counselors have rotating schedules across multiple schools or when a part-time school psychologist may have multiple schools and must focus primarily on providing assessment rather than intervention services.

The authors offer several strategies to facilitate collaboration between mental health supports and educators while working with students. These include using telehealth or telepsychology, collaborating with pediatricians, and facilitating collaboration with technological tools such as internet-based communication software and online document sharing tools.

\section{Collaboration Questions}

An old strategy, collaboration, appears to hold much potential as a new partnership solution to current and future challenges in rural education. A brief review of examples in the literature and articles in this special issue provide evidence of this potential. Last, I offer five example questions that if 
answered might advance the potential value of collaboration in future research, innovation and practice in rural education.

1. What knowledge, skills and dispositions must principals possess in rural settings to create a school culture of collaboration that supports innovation in teaching and learning?

2. What online collaboration strategies work best for teachers in rural settings to innovate solutions to their own problems of practice as a networked improvement community? 3. What policies, programs or practices facilitate collaborative actions among school district, school, and community leadership in rural locales that result in mutually beneficial outcomes for students and the community? 4. How might a team of scholars from different disciplines function as a research collaboratory to address critical rural education issues, such as workforce development in high poverty rural settings?

5. What methods, strategies and tools are most appropriate to evaluate if and how a

collaboration in a rural setting was effective or achieved key elements of success?

\section{References}

Association of Educational Service Agencies. (2017). AESA is a national organization for ESAs. Retrieved 2/22/2017 from http://www.aesa.us/

Butler, T. (2008). Rural schools and communities: How globalization influences rural school and community collaboration (Unpublished doctoral dissertation). The Pennsylvania State University, University Park, PA.

Chance, P. L., \& Segura, S. N. (2009). A rural high school's collaborative approach to school improvement. Journal of Research in Rural Education, 24(5). Retrieved from http://jrre.psu.edu/articles/24-5.pdf

Eargle, J. C. (2013). "I'm not a bystander": Developing teacher leadership in a rural schooluniversity collaboration. Rural Educator, 35(1). Retrieved from http://epubs.library.msstate.edu/index.php/rural educator/article/view/121

Green, B. R. (2013). Choice, challenge, and collaboration: Giving teachers of gifted students what they need in professional development (Unpublished doctoral dissertation). Mercer University, Macon, GA.

Harmon, H. L., \& Schafft. K. A. (2009). Rural school leadership for collaborative community development. The Rural Educator, 30(3), 4-9.

Kinsella-Meier, M. A., \& Gala, N. M. (2016). Collaboration: Definitions and explorations of an essential partnership. Odyssey: New Directions in Deaf Education, 17, 4-9.

Mattessich, P. W. \& Monsey, B. R. (1992). Collaboration: What makes it work. A review of research literature on factors influencing successful collaboration. Retrieved from ERIC database (ED390758). Available at http://files.eric.ed.gov/fulltext/ED390758.pdf.
Meyers, A B., Tobin, R. M., Huber, B. J., Conway, D. E., \& Shelvin, K. H. (2015). Journal of Educational \& Psychological Consultation, 25(2-3), 109-128.

Moser, M. E. (20112). Understanding how novice teachers utilize online collaboration (Unpublished doctoral dissertation). Southern Illinois University, Carbondale, IL.

Muijs, D. (2015). Collaboration and networking among rural schools: Can it work and when? Evidence from England. Peabody Journal of Education, 90(2), 294-305.

Schenke, W., van Driel, J. H., Geijsel, F. P., Sligte, H. W., \& Volman, M. L. L. (2016).

Characterizing cross-professional collaboration in research and development projects in secondary education. Teachers and Teaching: Theory and Practice, 22(5), 553-569.

Stephens, E. R. (1998). Expanding the vision: New roles for educational service agencies in rural school district improvement. Charleston, WV: Appalachia Educational Laboratory, The Rural Center at AEL.

Stephens, E. R., \& Harmon, H. L. (1996, September). Cost analysis studies of programs and services of state networks of ESAs, Perspectives: $A$ Journal of Research and Opinion about Educational Service Agencies, 2, 7-21.

Stephens, E. R., \& Keane, W. G. (2005). The educational service agency: American education's invisible partner. Lanham, MD: University Press of America.

Walker, A. (2012). Collaborating with the community: Lessons from a rural school district. TESOL Journal, 3(3), 469-487. 


\section{About the author:}

Hobart L. Harmon is project director of the investing in innovation (i3) projects awarded to the Virginia Advanced Study Strategies, Inc. by the U.S. Department of Education. Dr. Harmon also is co-director of the Institute for the Advancement of Research, Innovation and Practice in Rural Education at the University of Central Florida. 